\title{
LESS IS MORE: Interseções entre o surgimento do design gráfico moderno e o minimalismo de Mies van der Rohe
}

\author{
Laila Rotter Schmidt \\ Faculdade Assis Gurgacz \\ lailarsc@yahoo.com.br
}

Resumo: A presente pesquisa visa investigar a influência do minimalismo, no sentido preconizado pelo arquiteto Mies Van der Rohe, no surgimento do design gráfico moderno, tomando como exemplo o trabalho de designers pioneiros como Paul Rand e Saul Bass. Seu principal objetivo é mapear os preceitos em meio aos quais surge o minimalismo na arquitetura e escultura, passando por movimentos como o construtivismo russo, o neoplasticismo holandês e a Bauhaus, para tentar compreender o seu papel no surgimento do design gráfico moderno norte-americano em meados do século XX. Buscando analisar o diálogo entre arte, arquitetura e design pelo viés da máxima minimalista less is more, esta pesquisa, que se encontra atualmente em fase de conclusão, justifica-se principalmente por abordar o design como ponto de convergência e integração de diversas formas artísticas, buscando oferecer, através de seus resultados, contribuições com o estudo das artes visuais.

Palavras-chave: Minimalismo, Design gráfico moderno, Mies van der Rohe, Paul Rand, Saul Bass.

\begin{abstract}
This research aims to investigate the influence of minimalism, as defined by the architect Mies van der Rohe, over the emergence of modern graphic design, taking as an example the work of pioneering designers like Paul Rand and Saul Bass. Its main objective is to map the precepts amid which arises minimalism in architecture and sculpture, through movements such as Russian Constructivism, Bauhaus and the Dutch neoplasticism, trying to understand their role in the emergence of the modern American graphic design in the mid twentieth century. Seeking to analyze the dialogue between art, architecture and design through the minimalist statement 'less is more', this research, that is currently nearing completion, is justified mainly by discussing the design as a point of convergence and integration of various artistic forms, seeking to offer, through their results, contributions to the study of the visual arts.
\end{abstract}

Keywords: Minimal art, Modern graphic design, Mies van der Rohe, Paul Rand, Saul Bass. 


\section{INTRODUÇÃO}

Atualmente, em especial no campo do design gráfico, o termo "minimalismo" é utilizado de forma indiscriminada para caracterizar qualquer criação gráfica que utilize meios de expressão simples e econômicos. David Batchelor começa seu livro sobre o minimalismo na escultura discutindo esta problemática: "Quase qualquer coisa rotulada de minimal será automaticamente vista por alguns como austera, monocromática, abstrata, e assim por diante, independente de sua aparência efetiva" (2001, p. 7).

Apesar da vasta utilização do termo, há poucas contribuições no campo científico sobre o que efetivamente seja o minimalismo, em especial no design gráfico. Neste sentido, partindo de um mapeamento da pluralidade do termo minimal no contexto da arte e do design, este trabalho propõe-se a apontar interseções entre o minimalismo do arquiteto Mies van der Rohe e os primórdios do design gráfico moderno norte-americano, tomando como exemplos os designers Paul Rand e Saul Bass. Com isto almeja-se contribuir com o estudo do design como expressão plural, valorizando a riqueza proveniente de seu diálogo com outras formas artísticas.

A despeito da sua pluralidade, o termo minimalismo geralmente é associado à obra de Mies van der Rohe, ainda que, como veremos, a denominação ter surgido antes, no contexto da escultura. É expressiva a sua importância para a arquitetura moderna, bem como para inúmeras expressões visuais que tomam a arquitetura como referência, entre elas o design gráfico. No contexto desta jovem profissão, alguns dos primeiros profissionais a serem caracterizados como minimalistas são Paul Rand e Saul Bass. Os designers americanos possuem enorme importância no desenvolvimento do design gráfico moderno, sendo que suas influências são encontradas até hoje.

O termo minimal art - em português, minimalismo - foi utilizado pela primeira vez em 1965, no título de um manifesto escrito pelo filósofo Richard Wollheim (BATCHELOR, 2001, p. 6). Apesar de inaugurar a nomenclatura, o texto não mencionava os artistas ou as características estilísticas que efetivamente seriam considerados minimalistas pouco tempo depois. Neste sentido, em seu livro intitulado Minimalismos, Anatxu Zabalbeascoa e Javier Rodriguez Marcos afirmam:

\footnotetext{
Expressões como pureza geométrica, precisão técnica, essência estrutural, repetição de elementos e materiais, abstração e depuração ornamental foram e são frequentemente resumidos em - quando não identificados com - uma única palavra cuja fortuna na linguagem quotidiana foi além da sua própria definição: minimalismo. (2001, p. 18, tradução nossa)
}

Buscando a máxima expressão formal utilizando o mínimo de recursos e evitando qualquer alusão ou ilusão, a tendência minimalista manifestou-se em diversos campos artísticos desde o início do século XX, muito antes de a nomenclatura sequer existir. Com frequência o termo minimalista foi utilizado para denominar um conjunto de obras escultóricas desenvolvidas nos anos 60 por artistas norteamericanos, que negavam a tradição antropomórfica e expressionista então predominante na escultura: Carl Andre, Donald Judd, Dan Flavin, Sol LeWitt e Robert Morris. (ZABALBEASCOA; MARCOS, 2001, p. 20) 
Além da escultura, também a arquitetura moderna mantém estreita relação com o que hoje se entende por minimalismo. Com um bom grau de certeza poderia ser dito que as formas sóbrias que tiveram sucesso nos últimos tempos não procedem da escultura minimalista que surgiu nos anos sessenta, mas da arquitetura modernista.

Um dos mais rigorosos minimalistas do século é um arquiteto cuja morte quase coincidiu com o nascimento do termo minimal art: Mies van der Rohe. Segundo Vittorio E. Savi, uma das expressões que melhor sintetiza o espírito minimalista, Less is more, foi cunhada por Mies, (1996, p. 12) considerado um dos grandes mestres da arquitetura moderna. "As construções que hoje em dia são etiquetadas de minimalistas têm os seus antecedentes não tanto nos cubos de Donald Judd, Robert Morris ou Sol Le Witt mas nos projetos de Adolf Loos, Le Corbusier ou Mies van der Rohe". (ZABALBEASCOA; MARCOS, 2001, p. 56, tradução nossa)

As características geralmente atribuídas às obras minimalistas encontram-se enraizadas na tendência modernista que surge com a revolução industrial e têm desdobramentos em diversos campos artísticos.

\footnotetext{
É mais provável que, apesar da palavra [minimalismo] ter sido cunhada naquele momento, o conceito que designa tenha sido cristalizado com o calor de uma tendência a abstração em todas as artes desde o princípio do século XX: da pintura e a escultura até à arquitetura passando pelo teatro, a música ou o desenho industrial, do construtivismo russo à Bauhaus passando pelo neoplasticismo holandês. (ZABALBEASCOA; MARCOS, 2001, p. 56, tradução nossa)
}

Apesar de ser mais comum a referência à escultura e à arquitetura, o minimalismo também pode ser encontrado em outras manifestações artísticas, da literatura à sétima arte. "Disse Alfred Hitchcock que no cinema tudo que não é somado é subtraído". (ZABALBEASCOA; MARCOS, 2001, p. 77, tradução nossa) Neste sentido, Savi afirma que apesar de muitos artistas poderem ser considerados minimalistas em razão das características formais de suas obras, muito provavelmente nenhum deles reivindicou esta denominação, e sim a recebeu a posteriori.

\begin{abstract}
Como aconteceu na escultura primária norte-americana dos anos sessenta; na narrativa pós-Hemingway e pré-descontrutivista de Raycond Carver e seus seguidores; na "Koncrete Architektur" suíça (desde os experimentos edificatórios abstratos e concretos de Max Bill até as construções e peles arquitetônicas de Herzog \& De Meuron); ou nos projetos de Barcelona (da reconstrução do Pavilhão Germânico em 1985 até alguns dos projetos olímpicos de 1992), ninguém aspirou apropriar-se de uma tradição minimalista que busca a síntese entre o mínimo esforço econômico e o máximo efeito artístico. (SAVI, 1996, p. 14, tradução nossa)
\end{abstract}

Também de acordo com Batchelor, desde a metade dos anos 60 "o adjetivo minimalista tem sido estirado em todas as direções para cobrir um conjunto tão amplo de escultura e pintura (e outras formas de arte) que perdeu qualquer limite a que alguma vez possa (ou não) se ter se proposto." (2001, p. 6)

De modo geral, apesar da complexidade que aparentemente cerca a definição do que é minimalismo, as obras minimalistas facilmente são identificadas por sua economia formal. "A identificação entre simplicidade e minimalismo, como toda a generalização, ultrapassa suas próprias contradições e extrapola as artes e os artistas". (ZABALBEASCOA; MARCOS, 2001, p. 18, tradução nossa) "Quase todo trabalho 
aproximadamente geométrico, vagamente austero, mais ou menos monocromático e de aparência geral abstrata foi ou é provável que seja rotulado de minimal". (BATCHELOR, 2001, p. 6)

A utilização do mínimo de meios, no entanto, não pressupõe um efeito também mínimo, pelo contrário, busca obter o máximo de expressão, dizer mais com menos. Assim, abandonando o que não é essencial, potencializa o que realmente importa. "As formas a princípio mais neutras e, portanto, anônimas e sem estilo, acabam por converter-se nas mais marcantes e inconfundíveis". (ZABALBEASCOA; MARCOS, 2001, p. 18, tradução nossa)

\section{DESENVOLVIMENTO}

Para além das características formais, o minimalismo também foi acompanhado de preceitos teóricos, que acabam por distanciar a minimal art escultórica de sua equivalente arquitetônica.

$\mathrm{Na}$ escultura, a procura da máxima expressividade por meio da abstração geométrica rejeita qualquer leitura histórica, metafórica ou expressionista. A forma não era escolhida em razão de algum significado oculto ou inerente, mas em decorrência da sua qualidade de objeto. Deste modo, os seus efeitos podem ser sintetizados, necessariamente, na percepção visual, pois os objetos nada são além daquilo que deles pode ser percebido.

Fugindo de todo o ilusionismo, os objetos interessavam em função do seu material, da sua forma, da sua cor e do seu volume, apreendidos pelo que são, e não pelo que possam representar. [...] Tratava-se de passar da representação à apresentação, da esfera das aparências à esfera das realidades. (ZABALBEASCOA; MARCOS, 2001, p. 27, tradução nossa)

Se as esculturas minimalistas tentaram eliminar qualquer referência alheia à sua própria qualidade de objeto, a arquitetura, possivelmente antes que qualquer outra arte, quis eliminar toda a referência aos estilos clássicos para liberar-se da conformação dos estilos históricos, que até aquele momento marcavam a forma, a composição e os materiais em função de um rígido repertório.

\footnotetext{
A escultura libertava-se da sujeição ao antropomorfismo, traduzido em estátuas e monumentos, por meio de uma abstração absoluta alheia a todo o símbolo e a toda a função que fosse além da forma pura. E a arquitetura agarrou à via do funcionalismo como caminho de libertação: a forma seria concebida estritamente de acordo com a função, sem concessões estilísticas e representativas. (ZABALBEASCOA; MARCOS, 2001, p. 57, tradução nossa)
}

A tendência formalista, segundo a qual "a forma ideal de qualquer objeto deve ser determinada pela sua função", (CARDOSO, 2004, p. 120) seria a base para a formação do que ficou conhecido como International style com as obras de Mies nos estados unidos em meados do século XX. Form follows function era a máxima da Escola de Chicago, corrente que se desenvolveu nos estados unidos na virada do século e se desenvolveu muito mais nos escritórios do que nas escolas, cujo maior expoente foi Luis Sullivan. (SOUZA, 2008, p. 51)

Inaugurando uma das mais importantes expressões da arquitetura modernista, o estilo internacional se caracterizava pela abstração, a economia de linguagem e 
meios, a produção industrial, o uso literal dos materiais e a ausência de ornamento, colocando em prática muitos dos preceitos minimalistas.

No minimalismo é conservada uma versão reduzida e ao mesmo tempo
ampliada da modernidade: a falta de ornamento - uma aplicação rigorosa e
intensificada-, a utilização de volumes geométricos simples - reduzidos às
geometrias retilíneas-, os ângulos preferencialmente retos e a suposta
universalidade da linguagem. (ZABALBEASCOA; MARCOS, 2001, p. 87,
tradução nossa)

Foi Mies van der Rohe quem conduziu a abstração e a essencialidade aos seus limites mais extremos. Trata-se do "arquiteto que tem maior influência no estilo internacional e, devido ao seu cuidado com os pormenores e os materiais, é o que mais se aproxima das preocupações dos atuais minimalistas". (ZABALBEASCOA; MARCOS, 2001, p. 62, tradução nossa) O legado mais contundente à paisagem urbana do modernismo convertido em estilo internacional são os arranha-céus.

\footnotetext{
Os prismas puros que Mies edificou nos números 860 e 880 do Lake Shore Drive em Chicago (1951) e, sobretudo, o Seagram de Nova lorque (1958) conseguiam uma máxima presença do minimalismo através da transparência das superfícies, o contorno geometricamente puro das silhuetas e utilização de materiais industriais. (ZABALBEASCOA; MARCOS, 2001, p. 49, tradução nossa)
}

A universalidade no estilo internacional foi tão influente no pensamento arquitetônico da época, que não demorou muito para que se desgastasse, iniciando a crise do modernismo. Na época do surgimento do minimalismo escultórico, o estilo internacional era algo que tinha acabado convertendo-se numa teoria usada de forma massificada e indiscriminada em todo o mundo. "Além de sua degeneração que causou a aplicação inflexível das suas doutrinas, os mestres do movimento moderno promoveram uma tendência à simplicidade que ainda hoje perdura". (ZABALBEASCOA; MARCOS, 2001, p. 57, tradução nossa)

A arquitetura de Mies não se limitava ao rigor formal, mas era sustentada por um pensamento teórico, o que contribuiu para que sua produção não se esgotasse como a de seus seguidores. É precisamente este pensamento que distancia o minimalismo escultural do arquitetônico, conforme mencionado anteriormente.

A definição e que "a arquitetura é uma expressão espacial de uma decisão intelectual", formulada por Mies em 1928, revela um caráter transcendental da sua arquitetura, que visa ir além da forma pura, por mais econômica que esta seja.

Se a decisão intelectual estabelece uma ordem, esta ordem se materializa
num trabalho preciso simples e consciente do seu objetivo, de tal forma que
os mínimos elementos consigam uma expressão máxima. [...] No caso de
Mies van der Rohe, com toda a clareza que não ocorrerá os escultores
minimalistas norte-americanos, é produzida uma analogia entre
pensamento racional e obra construída. (ZABALBEASCOA; MARCOS, 2001, p.
63, tradução nossa)

A regularidade, a abstração e a lei construtiva pura buscam alcançar a máxima desmaterialização possível. O processo de abstração visava, assim, reduzir o objeto para revelar a "forma essencial" oculta nele, sendo a geometria simples a mais forte expressão dessa ideia fundamental e objetiva. O belo, neste sentido, não é uma 
criação subjetiva, mas uma realidade em si, algo ideal e objetivo que o arquiteto não cria, apenas revela.

Nas obras de Mies, a beleza manifesta-se mais pela subtração que pela
adição, num processo muito rigoroso que elimina tudo que não é essencial.
E neste ponto os caminhos voltam a separar-se. Para os minimalistas [na
escultura], o fim é a forma pura, o objeto específico. Para o arquiteto, a
forma nunca se refere a si mesma, e a sua essencialidade procede daquilo
ao que remete, uma espécie de princípio essencial e objetivo do volume ou
do espaço, ou seja do arquitetônico. (ZABALBEASCOA; MARCOS, 2001, p. 65,
tradução nossa)

Neste sentido, Mies nega o puro formalismo e visa uma economia de linguagem fazendo com que a forma derive não da função, mas da estrutura. Deste modo, na redução ao puramente imprescindível, se conseguiria uma arquitetura cuja contribuição estilística seria não a proposição de um estilo mas a procura da sobriedade e da abstração neutra, que dá prioridade à experiência direta do espaço e dos materiais. Disse ele: "Não me oponho à forma, mas unicamente à forma como meta. [...] A forma como meta origina sempre em formalismo. Isso implica um esforço que não se origina no interior, senão no exterior. Mas somente um interior vivo pode ter um exterior vivo." (apud ZABALBEASCOA; MARCOS, 2001, p. 68, tradução nossa)

Abstração, geometria elementar retilínea, estandardização industrial, precisão nos acabamentos, literalidade na utilização dos materiais, austeridade e ausência de ornamento são características comuns ao minimalismo escultórico e ao ideário do movimento moderno arquitetônico. Apesar de ter sido Mies van der Rohe quem colocou em prática esse ideário como nenhum outro arquiteto do século $X X$, suas origens antecedem 0 trabalho deste arquiteto. $O$ purismo formal e a ausência de decoração são ideias que surgem em Adolf Loos, que por sua vez influenciou um dos mais importantes arquitetos modernistas, Le Corbusier. "Em 1925, quando Le Corbusier decretou no seu ensaio $A$ arte decorativa atual que a decoração moderna não está decorada, citou precisamente Loos como um precursor". (ZABALBEASCOA; MARCOS, 2001, p. 59, tradução nossa)

Tais buscas rompiam completamente com os padrões classicistas da época. Esta ruptura transcendia a necessidade estética e relacionava-se também com a nova filosofia racional e industrial da modernidade. Dizia Loos: "A carência de ornamento tem como consequência a diminuição do tempo de trabalho e o aumento do ordenado". (apud ZABALBEASCOA; MARCOS, 2001, p. 62, tradução nossa) Além da economia de produção, a ausência de ornamento também servia à maior durabilidade da arquitetura, já que o estilo sóbrio suportaria melhor as flutuações da moda e mudanças de gosto.

A renúncia de Loos às velhas tendências construtivas vienenses para conseguir uma nova linguagem com os novos materiais que foram se impondo a partir da revolução industrial operada na virada do século, certamente tem grande influência sobre a opção de Mies nos anos cinquenta em escolher "uma forma intensa, mais que extensa". (apud ZABALBEASCOA; MARCOS, 2001, p. 9, tradução nossa)

As raízes do minimalismo, em especial no que diz respeito às preocupações do design gráfico, remetem às primeiras tentativas de conciliar arte e indústria que, segundo historiadores do design como Rafael Cardoso e Pedro Luiz Pereira de Souza, tiveram origem na Deutcher Werkbund, (1907) "uma espécie de associação 
profissional" criada na Alemanha congregando artistas, artesãos, arquitetos e designers. (SOUZA, 2008, p. 38)

Buscando promover a aproximação entre arte e indústria, Hermann Muthelsiuis, um dos maiores expoentes da Werkbund, "propunha uma concepção simplificada dos produtos, maneira de torná-los mais adequados tanto em aspectos técnicos como de custo ao incremento do seu consumo". (SOUZA, 2008, p. 37) Com isso, a ideia naturalista de arte reproduzindo uma determinada realidade é substituída pela ideia de arte sendo uma própria realidade, ou seja, produzindo significados contidos em si mesma, o que deu origem ao que foi chamado de 'Teoria da Pura Visualidade'".

Nesta corrente se insere a total ausência de ornamento defendida por Loos, que preconizou as ideias de Le Corbusier e Mies, juntamente com Peter Behrens, que foi um dos primeiros a aceitar a industrialização como requisito para a sobrevivência do design. "Behrens era um dos mais importantes arquitetos alemães, membro ativo do Werkbund, que escreveu um ensaio, em 1910, chamado Forma e técnica introdutório aos conceitos formais que se estabeleceriam como tema maior de discussão para o design moderno." (SOUZA, 2008, p. 49) No início do século, Walter Gropius, Le Corbusier e Mies Van der Rohe trabalharam no escritório de arquitetura de Behrens, onde, de acordo com Souza, se deu seu "aperfeiçoamento profissional e conceitual" sob os preceitos da Werkbund. (2008, p. 58)

Além de arquiteto, Behrens trabalhou também como designer gráfico, tendo sido responsável pela imagem visual da AEG, incluindo projeto gráfico de catálogos e mostruários. "Pode-se considerar a obra desenvolvida para a AEG como o início prático do design moderno. Esta obra significou a adoção, pela iniciativa privada, dos princípios éticos e formais enunciados pela Werkbund". (CARDOSO, 2004, p. 110)

Em 1919, surge a Bauhaus, inaugurando um dos períodos mais significativos para o ensino do design moderno, que integrou diversas manifestações artísticas no mesmo curso. "A ideia de que o design devesse ser pensado como uma atividade unificada e global, desdobrando-se em muitas facetas, mas atravessando ao mesmo tempo múltiplos aspectos da atividade humana". (CARDOSO, 2004, p. 118)

\footnotetext{
Costuma-se dividir a história da Bauhaus em três períodos, coincidentes com suas três sedes: Weimar (1919-1923), Dessau (1923-1929) e Berlim (19291933). Estes três períodos foram caracterizados também por uma influência maior do expressionismo tardio (na época de Weimar), do fordismo estético, derivado em sua essência do Projeto Werkbund (em Dessau) e das consequências do racionalismo radical, iniciado ainda em Dessau (1927) e que se prolonga até a extinção da escola (em Berlim). (SOUZA, 2008, p. 37)
}

A reforma da Bauhaus, que aconteceu em 1923, sofreu influências das chamadas vanguardas históricas, nas quais enquadram tendências derivadas do construtivismo - em especial o holandês (De Stijl) e o suíço ( $A B C$ ) - que negava a arte no sentido puro e propunha uma arte produtiva. "A Bauhaus não aderiu totalmente ao construtivismo: reelaborou um formalismo construtivista; criou um novo critério de composição da forma, inspirado na técnica, para substituir o anterior, inspirado no artesanato". (SOUZA, 2008, p. 73)

No contexto das relações entre arte e produção, merece destaque também o pensamento de Le Corbusier. "Para Le Corbusier, inspirar-se nas máquinas sempre quis dizer incorporar às artes (arquitetura, pintura e escultura) algumas propriedades 
formais das máquinas." (CARDOSO, 2004, p. 64) Este pensamento identifica-se em sua natureza plástica e formal com o que mais tarde se denominou "estilo Bauhaus" para caracterizar o pensamento da Bauhaus na época em que esteve sob a direção de Groppius.

A Bauhaus foi dirigida nos seus últimos anos por Mies, que logo após o fechamento da escola em 1933 exilou-se nos estados unidos e começou a desenvolver o estilo internacional. Os preceitos da Bauhaus são em grande parte fundamentos do seu pensamento modernista na arquitetura.

A teoria do design da Bauhaus exerceu enorme influência no campo do design gráfico, bem como outros movimentos modernos que, como vimos, estão vinculados ao seu surgimento, como o Construtivismo russo e o Neoplasticismo holandês, e outros que se desenvolveram a partir de seus preceitos, como o Estilo internacional.

Entre a arquitetura e o design, um dos caminhos pelos quais o minimalismo transitou é precisamente o Estilo internacional, que extrapolou as fronteiras da arquitetura, manifestando-se também em outras expressões artísticas como o design gráfico.

Em termos de design gráfico, o Estilo internacional se manifestou principalmente através da austeridade, do rigor e da precisão associadas à chamada 'escola suíça', termo um tanto genérico utilizado para se referir aos trabalhos realizados entre as décadas de 1920 e 1960 por designers [...] que impuseram definitivamente o grid como parâmetro construtivo. (CARDOSO, 2004, p. 153)

Do estilo internacional surge uma corrente conhecida como Good Design, da qual um dos principais expoentes foi o arquiteto e designer gráfico Max Bill. "O design gráfico e arquitetônico de Max Bill, entre a Bauhaus e Le Corbusier, se baseia no máximo rigor geométrico para obter, nada menos que Die gute form" [bom design]. (SAVI, 1996, p. 15, tradução nossa) Amplamente difundido nos estados unidos entre as décadas de 50 e 60, o Good Design se manifestou no trabalho do designer Paul Rand, que exerceu enorme influência no design da metade do século XX e com frequência é reconhecido um dos fundadores do design moderno.

Perto do fim da década [de 1940, Rand], elaborou um vocabulário de design gráfico baseado na forma pura, onde antes apenas o estilo e a técnica prevaleciam. Em meados dos anos 50, alterou a maneira pela qual as grandes corporações usavam a identidade visual e, ao longo dos anos 1960, criou algumas das marcas corporativas mais fortes e duradouras no mundo todo, incluindo as da IBM, UPS, ABC e Westing-house. [...]A cultura corporativa incipiente reconheceu no design funcionalista atrativos irresistíveis como austeridade, precisão, neutralidade, disciplina, ordem, estabilidade e um senso inquestionável de modernidade, todas as qualidades que qualquer empresa multinacional desejava transmitir para os clientes e funcionários". (CARDOSO, 2004, p. 154)

Considerado herdeiro de Mies, Le Corbusier, Loss e do Projeto Werkbund, Rand é reconhecido como um dos mais destacados exemplos de transposição dos movimentos vanguardistas das artes visuais e da arquitetura para o design gráfico. De acordo com Steven Heller, "a aproximação de Rand ao design editorial emprestou mais dos pensadores e arquitetos modernos como Le Corbusier e Mies van der Rohe que dos mais famosos editores" (1999, p. 124, tradução nossa). Para Michael Kroeger, 
Rand foi "o canal através do qual a arte e o design modernos na Europa - o construtivismo russo, o De Stijl holandês e a Bauhaus alemã - foram introduzidos na arte comercial norte-americana". (2010, p. 13)

Inspirando-se no exemplo de artistas como o pintor Paul Klee, o designer El Lissínski, e o arquiteto Le Corbusier - todos eles preconizadores de um "espírito atemporal" no design - Rand era fiel ao preceito de Le Corbusier, de que "ser moderno não é uma moda, é um estado". (MICHAEL, 2010, p. 13) Além das referências em comum, as características formais e o caráter funcionalista do design de Rand também o aproximam do minimalismo arquitetônico.

\footnotetext{
Buscando inspiração nos modernos Europeus, ele desenvolveu uma abordagem revigorante e individual da comunicação visual. Seus projetos para revistas e publicidade uniam simplicidade funcional á complexidade da abstração. Eles não buscavam um denominador comum. Desprovidos de ornamento, eram conceitualmente precisos e visualmente elegantes. Cada detalhe era estrategicamente planejado para atrair o olhar e veicular uma mensagem. (MICHAEL, 2010, p. 16)
}

Assim como Mies, Rand acreditava que o design deveria seguir objetivos bem definidos, e que a forma deveria solucionar os problemas de comunicação enfrentados, e não ser apenas uma livre expressão artística. Dizia Rand: "o casamento da forma com o conteúdo é a realização do design". (apud MICHAEL, 2010, p. 47) Sua obra unia simplicidade formal, complexidade de abstração e ausência de ornamentos, resultando em um design conceitualmente preciso e visualmente elegante. "Cada detalhe era estrategicamente planejado para atrair o olhar e veicular uma mensagem". (MICHAEL, 2010, p. 16)

Outro grande expoente do design gráfico norte-americano pós-guerra, Saul Bass, também demonstra ser digno do rótulo minimalista, e de fato foi assim caracterizado por alguns críticos. Bass é reconhecido por ter realizado uma das mais produtivas interseções entre as linguagens visuais do cinema e do design gráfico por meio da criação de cartazes e aberturas de grandes títulos do cinema norte-americano. Trabalhou com diretores como Otto Preminger, Billy Wilder, Alfred Hitchcock, Stanley Kubrick e Martin Scorsese - quem considera a sua reputação como "designer de filmes" lendária (1993).

Com a sequência de abertura criada por Bass para 'The man with the golden arm' (1955), este elemento do filme, até então negligenciado, passou a ser encarado como parte integrante da obra audiovisual - elemento de identidade do filme, responsável por gerar expectativa, provocar curiosidade e preparar o público para a narrativa que vem a seguir. Para FERREIRA (2008), Bass exerceu ampla influência sobre a linguagem fílmica ao lançar um olhar original sobre a forma e sentido cinematográficos a partir de sua formação no design gráfico moderno.

As incursões de Bass na linguagem fílmica se expressam também nos seus cartazes, caracterizados pela abstração, minimalismo, pureza formal e simbolismo estratégias visuais adotadas pelo designer para captar a "essência" do filme e apresentá-la de forma provocativa, com o propósito de motivar o público a vê-lo. Aproximando-se da vanguarda, que recusa a imitação da aparência e busca construir sentidos a partir de uma expressão visual simbólica, Bass coloca-se na contramão das tendências de design de cartazes da época. Para Jennifer Bass e Pat Kirkham não se pode associar a estética de Bass a uma única tendência, mas elementos recorrentes 
ligados ao modernismo podem ser apontados, tais como "uma forte tendência para a redução, destilação, economia e minimalismo." (2011, p. XV)

Da mesma forma que Rand, Bass foi influenciado pelo surrealismo e o construtivismo russo. Também embasou seu trabalho na obra de seu mentor e compatriota, o fotógrafo László Moholy-Nagy. Depois de se mudar para Los Angeles, em 1946, Bass abraça o modernismo e vira-se para um espírito de vanguarda progressista. Neste período, Bass participou graficamente da revista Arts \& Architecture, em torno da qual forma-se um grupo modernista que "promove o cruzamento entre design, arquitetura, música e fotografia", juntando o fotógrafo Moholy-Nagy, o pintor Hans Hofmann e o arquiteto Mies van der Rohe na mesma publicação, tal como trabalhos do fotógrafo Herbert Matter e do designer Alvin Lustig, influências decisivas em Bass. (VALENTE, 2012)

\section{CONCLUSÃO}

Parece ser consenso que foi Mies van der Rohe o grande responsável pela popularização do minimalismo enquanto proposta estética na arquitetura, ainda que tenham sido as formas do movimento escultórico de Le Witt e o pensamento industrial de Loss os grandes precursores do termo que mais tarde ia se tornar tão popular no pensamento moderno e contemporâneo.

O levantamento teórico realizado indica que, apesar das indefinições que cercam o termo, as linhas gerais do que é a minimal art podem ser traçadas em torno de algumas características comuns: abstração, geometria elementar retilínea, estandardização industrial, precisão nos acabamentos, literalidade na utilização dos materiais, austeridade e ausência de ornamento.

Enquanto o consenso no aspecto formal é relativamente simples de se obter, aquilo que justifica a escolha da forma parece ser o maior ponto de divergência. Enquanto a escultura minimalista fundamentou-se no puro formalismo, valorizando a potência expressiva da forma em si mesma, a arquitetura embasou suas formas econômicas no funcionalismo, valorizando a abstração racional. Ao passo que a potência simbólica e o potencial de comunicação universal foram os grandes responsáveis pelo design minimal ter caído no gosto dos designers gráficos e das grandes corporações, foi a discussão moderna acerca da relação entre arte e indústria a via pela qual o estilo minimalista estendeu-se ao design gráfico.

De fato, seja na escultura, arquitetura, design gráfico ou qualquer outra expressão artística na qual tenha se desenvolvido, o minimalismo esteve sempre enraizado no ideário modernista, e por consequência na lógica industrial, de modo que a economia de meios está diretamente relacionada à economia de tempo, energia e recursos. Talvez daí derive a sua popularidade ainda hoje, quase 50 anos depois do seu surgimento: superando os excessos pós-modernos, o pensamento contemporâneo parece valorizar cada vez mais aquilo que é justo, preciso e principalmente econômico.

Sendo esta uma pesquisa em desenvolvimento, as conclusões apresentadas ainda são preliminares, em especial no que diz respeito à aplicação desta leitura conceitual ao âmbito prático do trabalho de Rand e Bass. 


\section{REFERÊNCIAS}

BASS, Jennifer; KIRKHAM, Pat. Saul Bass: a Life in film \& design. London: Laurence King Publishing Ltd, 2011.

BATCHELOR, David. Minimalismo. Tradução: Célia Euvaldo. São Paulo: Cosac Naify, 2001.

CARDOSO, Rafael. Uma introdução à história do design. 2. ed. rev. e ampl. São Paulo: Edgard Blücher, 2004.

FERREIRA, F. A. A inserção do design moderno nos letreiros dos filmes brasileiros nos anos 1960. Anais do 9o Congresso Brasileiro de Pesquisa e Desenvolvimento em Design. São Paulo: Blücher e Universidade Anhembi Morumbi, 2010.

FERREIRA, F. A. Arte gráfica enquanto cinema e cinema enquanto arte gráfica: os letreiros cinematográficos de Saul Bass. São Paulo, 2008. Tese (Doutorado em Ciências da Comunicação) - ECA, USP.

HELLER, Steven. Paul Rand. London: Phaidon Press Limited, 1999.

HOLLIS, Richard. Design gráfico: Uma história concisa. São Paulo: Martins Fontes, 2000.

KROEGER, Michael (org.). Conversas com Paul Rand. Tradução: Cristina Fino. São Paulo: Cosac Naify, 2010.

LUPTON, Ellen e MILLER, J. Abbot. ABC da Bauhaus: A Bauhaus e a teoria do design. São Paulo: Cosac Naify, 2008.

MELO, Chico Homem de. 0 design gráfico brasileiro: anos 60. São Paulo: Cosac Naify, 2008.

MONZANI, J. M. A. S. Cinema e Design Gráfico: Correlações - Inglaterra nos anos 70. www.mnemocine.com.br, São Paulo, SP, v. 16, p. 30, 2006.

ROVIRA, Josep M.; CASALS, Lluís. Reflections Mies van der Rohe Pavillion. Pittsburg: Triangle Postals, 2002.

SAVI, Vittorio. Minimalism in Architecture and the Other Arts. Barcelona: Less is more, 1996

SCORSESE, M. Saul Bass as a designer of films. In: Saul Bass. World Graphic Design 10. Tokyo: Ginza Graphic Gallery, 1993.

SOUZA, Pedro Luiz Pereira de. Notas para uma história do design. 4. ed. Rio de Janeiro: 2AB, 2008.

ZABALBEASCOA, Anatxu; MARCOS, Javier Rodríguez. Minimalismos. Barcelona: Gustavo Gili S.A, 2001

VALENTE, Francisco. O olho vivo de Saul Bass. Portal Ípsilon. 13/04/2012. Disponível em: <http://ipsilon.publico.pt/cinema/texto.aspx?id=303361> Acesso em: 10/09/2013 